\title{
KRAS codon 6I, 146 and BRAF mutations predict resistance to cetuximab plus irinotecan in KRAS codon 12 and 13 wild-type metastatic colorectal cancer
}

\section{F Loupakis*, 1,8, A Ruzzo ${ }^{2,8}$, C Cremolini', B Vincenzi ', L Salvatore', D Santini ', G Masi', I Stasi', E Canestrari',

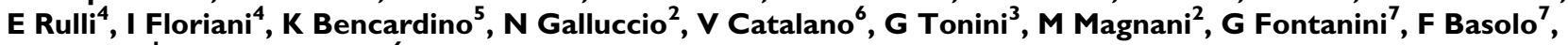 A Falcone' and F Graziano ${ }^{6}$}

'Unit of Medical Oncology 2, Azienda-Ospedaliero Universitaria Pisana, Istituto Toscano Tumori and Department of Oncology, Transplantes and New Technologies in Medicine, University of Pisa, Via Roma 67 - 56126 Pisa, Italy; ${ }^{2}$ Section of Biochemistry and Molecular Biology "G. Fornaini", Department of Biomolecular Sciences, University of Urbino, Via Saffi 2 - 61029 Urbino Italy; ${ }^{3}$ Unit of Medical Oncology, University Campus Biomedico, Via Alvaro del Portillo 200 - 00128 Rome, Italy; ${ }^{4}$ Mario Negri Institute for Pharmacological Research, Via La Masa 19-20156 Milan, Italy; ${ }^{5}$ Unit of Medical Oncology, San Raffaele Scientific Institute, Via Olgettina 60 - 20132 Milan, Italy; ${ }^{6}$ Unit of Medical Oncology, Hospital of Pesaro, Via Lombroso I - 61 I 00 Pesaro, Italy; ' Division of Pathology, Department of Surgery, University of Pisa, Istituto Toscano Tumori, Via Roma 67 - Pisa, Italy

BACKGROUND: KRAS codons 12 and 13 mutations predict resistance to anti-EGFR monoclonal antibodies (moAbs) in metastatic colorectal cancer. Also, BRAF V600E mutation has been associated with resistance. Additional KRAS mutations are described in CRC. METHODS: We investigated the role of KRAS codons $6 I$ and 146 and BRAF V600E mutations in predicting resistance to cetuximab plus irinotecan in a cohort of KRAS codons 12 and 13 wild-type patients.

RESULTS: Among 87 KRAS codons 12 and 13 wild-type patients, KRAS codons 61 and 146 were mutated in 7 and I case, respectively. None of mutated patients responded vs 22 of 68 wild type $(P=0.096)$. Eleven patients were not evaluable. KRAS mutations were associated with shorter progression-free survival (PFS, HR: 0.46, $P=0.028$ ). None of 13 BRAF-mutated patients responded vs 24 of 74 BRAF wild type $(P=0.016)$. BRAF mutation was associated with a trend towards shorter PFS (HR: $0.59, P=0.073)$. In the subgroup of BRAF wild-type patients, KRAS codons 6 I// 46 mutations determined a lower response rate $(0$ vs $37 \%, P=0.047)$ and worse PFS (HR: $0.45, P=0.023)$. Patients bearing KRAS or BRAF mutations had poorer response rate $(0$ vs $37 \%, P=0.0005)$ and $P F S$ (HR: $0.5 \mathrm{I}, P=0.006)$ compared with KRAS and BRAF wild-type patients.

CONCLUSION: Assessing KRAS codons 6 I/ I 46 and BRAF V600E mutations might help optimising the selection of the candidate patients to receive anti-EGFR moAbs.

British Journal of Cancer (2009) I 0 I, 7I5-721. doi:10.1038/sj.bjc.6605 I77 www.bjcancer.com

Published online 14 July 2009

(C) 2009 Cancer Research UK

Keywords: colorectal cancer; cetuximab; KRAS; BRAF

RAS and RAF proteins play a key role in the control of cellular growth, proliferation and differentiation (Bos, 1989; Wickenden et al, 2008) KRAS-activating mutations reduce or abolish intrinsic GTPase activity of the protein, leading to its constitutive activation (Conlin et al, 2005) Similarly BRAF V600E mutation induces structural changes in RAF protein which increase its kinase activity (Wan et al, 2004) Activated RAS and RAF are responsible for the disregulation of RAS/RAF/MAPKs signalling pathway.

KRAS codons 12 and 13 activating mutations are widely recognised as predictors of resistance to the treatment with antiEGFR monoclonal antibodies (moAbs) in metastatic colorectal cancer (mCRC) patients (Karapetis et al, 2008; Amado et al, 2008). Based on retrospectively collected data and post hoc analyses of large phase III studies, the European Medicines Agency has

\footnotetext{
*Correspondence: Dr F Loupakis;

E-mail: fotiosloupakis@gmail.com

${ }^{8}$ These authors contributed equally to this work

Received 17 April 2009; accepted 8 June 2009; published online I4 July 2009
}

restricted the use of cetuximab to the treatment of patients with KRAS codons 12 and 13 wild-type disease (about the $60 \%$ of the overall population; EMEA, 2008) and the American Society of Clinical Oncology has similarly recommended in a recent provisional clinic opinion not to administer anti-EGFR moAbs to patients with KRAS codons 12 or 13 mutated tumours (Allegra et al, 2009). Nevertheless, in a systematic review and meta-analysis, Linardou et al reported a very high specificity $(0.93,(0.83-0.97))$ and a much lower sensitivity $(0.47,(0.43-0.52))$ of KRAS analysis in predicting resistance to anti-EGFR moAbs in mCRC, thus underlining the need for additional predictive markers to be combined with KRAS codons 12 and 13 evaluation, for a more accurate patients' selection (Linardou et al, 2008).

A recently published experience found a correlation between $B R A F$ V600E-activating mutation, mutually exclusive with KRAS ones, and resistance to the treatment with cetuximab and panitumumab administered alone or in combination with chemotherapy (Di Nicolantonio et al, 2008).

On the basis of the above-mentioned evidences, around $50 \%$ of candidate patients would be excluded from receiving anti-EGFR 
moAbs, with a significant improvement of the treatment's cost effectiveness. However, as cetuximab or panitumumab monotherapies determine a response rate of about $10 \%$ regardless of the line of treatment and no more than $23 \%$ of patients respond to the combination of cetuximab and irinotecan (Cunningham et al, 2004; Van Cutsem et al, 2007; Jonker et al, 2007) it is plausible that the selection of candidate patients to receive an anti-EGFR moAb might be further slightly refined.

Additional KRAS-activating mutations, involving codons 61 and 146 (Edkins et al, 2006) occur with frequencies ranging from 1 to $4 \%$ in CRCs. These relatively rare mutations, as well as codons 12 and 13 mutations, are responsible for the oncogenic constitutive activation (Buhrman et al, 2007; Feig and Cooper, 1988) of RAS/ RAF/MAPKs pathway and they might account for up to a $10 \%$ of resistant patients bearing KRAS codons 12 and 13 and $B R A F$ wildtype tumours.

To optimise the selection of patients who are more likely to benefit from anti-EGFR we investigated in a cohort of patients treated with the combination of cetuximab and irinotecan and bearing KRAS codons 12 and 13 wild-type tumours, the association of KRAS codons 61 and 146 mutations and BRAF V600E mutation with clinical outcomes.

\section{MATERIALS AND METHODS}

\section{Patients}

Patients with irinotecan-refractory mCRC (ie, progressed during or within 3 months after treatment with an irinotecan-based regimen) were considered eligible for our study if they had an histologically confirmed diagnosis of EGFR-positive adenocarcinoma, measurable and evaluable disease according to RECIST criteria (Therasse et al, 2000) available paraffin-embedded samples of primary lesions and had undergone a salvage cetuximabirinotecan treatment.

All patients' samples were screened for KRAS codons 12 and 13 mutations, constituting the group named 'overall population' and only those with wild-type disease were included in the group named 'study population' and further analysed for KRAS codons 61, 146 and BRAF V600E mutations.

Response was evaluated every 8 weeks by CT-scan. According to RECIST criteria, patients were categorised as responders if they achieved complete response (CR) or partial response (PR), or nonresponders if they showed stable (SD) or progressive disease (PD). Progression-free survival (PFS) was defined as the time from the beginning of chemotherapy to first appearance of progression or death by any cause. Overall Survival (OS) was defined as the time from the beginning of therapy to death or last follow-up (censored observations).
Patients' characteristics and their outcomes were unknown to investigators performing genetic analyses. The study was approved by local Ethical Committees and patients provided signed informed consent to mutational analyses.

\section{Mutational analyses}

Mutational analyses were centralised and performed at the Laboratory of Molecular Biology, Institute of Biochemistry, University of Urbino.

DNA was extracted from tissue samples using the Qiamp DNA FFPE tissue Kit (Qiagen, Hilden, Germany) according to the manufacturer's protocol.

Hotspot mutation sites were amplified by polymerase chain reaction (PCR). Primer sequences and cycling conditions are shown in Table 1. Primers design was performed by mean of PSQ Assay Design Software (Biotage, Uppsala, Sweden).

Each PCR reaction contained 50-150 ng of DNA, $0.4 \mu \mathrm{m}$ of each primer, $12.5 \mu \mathrm{l}$ of PCR Master Mix (Diatheva, Fano, Italy) and $0.625 \mathrm{U}$ of HotStarTaq polymerase (Diatheva) in a total volume of $25 \mu \mathrm{l}$. Successful and specific amplification of the region of interest was verified by visualising $5 \mu \mathrm{l}$ of the PCR product on a $2 \%$ agarose gel.

Preparation of the single-stranded DNA template for pyrosequencing analysis was performed using the PSQ Vacuum Prep Tool (Biotage) according to the manufacturer's instructions. A portion of $20 \mu \mathrm{l}$ of biotinylated PCR product was immobilised on streptavidin-coated Sepharose High-Performance beads (Amersham Biosciences, Piscataway, NJ, USA) and processed to obtain a single-stranded DNA using the PSQ 96 Sample Preparation Kit (Biotage) according to the manufacturer's instructions.

The template was incubated with $0.4 \mu \mathrm{moll}^{-1}$ sequencing primer at $80^{\circ} \mathrm{C}$ for $2 \mathrm{~min}$ in a PSQ96 plate. The sequencing by synthesis reaction of the complementary strand was automatically performed on a PSQ 96MA instrument (Biotage) using PyroGold reagents (Biotage).

\section{Statistical analysis}

Results of KRAS and BRAF mutational analyses were used as categorical variables (presence or absence of the mutation). The primary end-point was the correlation between KRAS codon 61, 146, BRAF V600E mutations and response to treatment in the study population. Two-tailed Fisher's exact test was used to compare proportions of responders and non-responders according to their mutational status. The PFS and OS analyses were determined according to the Kaplan-Meier method and survival curves were compared using the log-rank test. Statistical significance was set at $P<0.05$ for a bilateral test.

Table I Primers and polimerase chain reaction (PCR) conditions for mutational analyses

\begin{tabular}{|c|c|c|}
\hline Mutations & Primers & PCR conditions \\
\hline KRAS codon $12-13$ & $\begin{array}{l}\text { F: 5'-GGCCTGCTGAAAATGACTGAA } \\
\text { R: 5'-[Btn]-TTCGTCCACAAAATGATTCTGA } \\
\text { Seq: 5'-TATAAACTTGTGGTAGTTGG }\end{array}$ & $\begin{array}{l}10^{\prime} \text { at } 95^{\circ} \mathrm{C}, 40 \text { cycles of } 15^{\prime \prime} \text { at } 95^{\circ} \mathrm{C}, 30^{\prime \prime} \text { at } 64^{\circ} \mathrm{C}, 40^{\prime \prime} \text { at } \\
72^{\circ} \mathrm{C} \text { and } 5^{\prime} \text { at } 72^{\circ} \mathrm{C}\end{array}$ \\
\hline KRAS codon 6I & $\begin{array}{l}\text { F: 5'-CAGACTGTGTTCTCCCTTCTCA } \\
\text { R: 5'-[Btn]CTCATGTACTGGTCCCTCATTG } \\
\text { Seq: 5'-ATATTCTCGACACAGCAG }\end{array}$ & $\begin{array}{l}10^{\prime} \text { at } 95^{\circ} \mathrm{C}, 40 \text { cycles of } 15^{\prime \prime} \text { at } 95^{\circ} \mathrm{C}, 30^{\prime \prime} \text { at } 66^{\circ} \mathrm{C}, 30^{\prime \prime} \text { at } \\
72^{\circ} \mathrm{C} \text { and } 5^{\prime} \text { at } 72^{\circ} \mathrm{C}\end{array}$ \\
\hline KRAS codon 146 & $\begin{array}{l}\text { F: 5'-TGGACAGGTITTGAAAGATATTTG } \\
\text { R: 5'-[Btn]-ATTAAGAAGCAATGCCCTCTCAAG } \\
\text { Seq: 5'-AATTCCTTTTATTGAAACAT }\end{array}$ & $\begin{array}{l}10^{\prime} \text { at } 95^{\circ} \mathrm{C}, 40 \text { cycles of } 15^{\prime \prime} \text { at } 95^{\circ} \mathrm{C}, 30^{\prime \prime} \text { at } 64^{\circ} \mathrm{C}, 30^{\prime \prime} \text { at } \\
72^{\circ} \mathrm{C} \text { and } 5^{\prime} \text { at } 72^{\circ} \mathrm{C}\end{array}$ \\
\hline BRAF codon 600 & $\begin{array}{l}\text { F: 5'-ATGCTTGCTCTGATAGGAA } \\
\text { R: 5'-[Btn]-GCATCTCAGGGCCAAA } \\
\text { Seq:5'-GGTGATITTGGTCTAGCTAC }\end{array}$ & $\begin{array}{l}10^{\prime} \text { at } 95^{\circ} \mathrm{C}, 40 \text { cycles of } 15^{\prime \prime} \text { at } 95^{\circ} \mathrm{C}, 30^{\prime \prime} \text { at } 54^{\circ} \mathrm{C}, 40^{\prime \prime} \text { at } \\
72^{\circ} \mathrm{C} \text { and } 5^{\prime} \text { at } 72^{\circ} \mathrm{C}\end{array}$ \\
\hline
\end{tabular}

Abbrevations: Btn = biotynilated; Seq = sequencing primer 
Table 2 Patients' characteristics

\begin{tabular}{|c|c|c|}
\hline & $\begin{array}{l}\text { Overall population } \\
\qquad \begin{array}{c}(N=138) \\
n(\%)\end{array}\end{array}$ & $\begin{array}{l}\text { Study population } \\
(\mathbf{N}=\mathbf{8 7}) \\
n(\%)\end{array}$ \\
\hline \multicolumn{3}{|l|}{ Age } \\
\hline Median (range) & $61(42-77)$ & $66(4 \mid-79)$ \\
\hline \multicolumn{3}{|l|}{ Sex } \\
\hline Male & $76(55)$ & $52(60)$ \\
\hline Female & $62(45)$ & $35(40)$ \\
\hline \multicolumn{3}{|l|}{ ECOG PS } \\
\hline 0 & $70(5 \mathrm{I})$ & $44(5 \mathrm{I})$ \\
\hline I & $61(44)$ & $39(44)$ \\
\hline 2 & $7(5)$ & $4(5)$ \\
\hline \multicolumn{3}{|l|}{$\begin{array}{l}\text { Number of metastatic } \\
\text { sites }\end{array}$} \\
\hline I & $33(24)$ & $21(24)$ \\
\hline 2 & $63(46)$ & $41(47)$ \\
\hline$\geqslant 2$ & $42(30)$ & $25(29)$ \\
\hline \multicolumn{3}{|l|}{ Sites of metastases } \\
\hline Liver & $110(80)$ & $63(72)$ \\
\hline Lung & $72(52)$ & $45(52)$ \\
\hline Lymph nodes & $35(25)$ & $24(27)$ \\
\hline Peritoneum/pelvis & $31(22)$ & $20(23)$ \\
\hline Other & $46(33)$ & $29(33)$ \\
\hline \multicolumn{3}{|l|}{ Skin toxicity } \\
\hline $\mathrm{G}_{0}-\mathrm{G}_{1}$ & $84(61)$ & $44(5 \mathrm{I})$ \\
\hline$\geqslant G_{2}$ & $54(39)$ & $43(49)$ \\
\hline
\end{tabular}

\section{RESULTS}

A total of 138 patients with mCRC, who had received cetuximab and irinotecan in four Italian Medical Oncology Units, have been screened for KRAS codons 12 and 13 mutations.

Clinical and pathological characteristics of the overall population and of the study population are summarised in Table 2.

Eighty-seven (63\%, 52 men and 35 women) of 138 patients had KRAS codons 12 and 13 wild-type disease and entered the study population. Median age was 66 (range: $41-79$ ). Of these 87, 44 (51\%), 39 (44\%) and $4(5 \%)$ patients had an ECOG PS of 0,1 and 2, respectively.

All patients received cetuximab plus irinotecan according to the schedule commonly used in clinical practice: cetuximab $250 \mathrm{mg} / \mathrm{sqm}$ i.v., day 1 weekly (loading dose: $400 \mathrm{mg} / \mathrm{sqm}$ i.v., day 1 in the first cycle) or $500 \mathrm{mg} / \mathrm{sqm}$ i.v., day 1 every 2 weeks and irinotecan $180 \mathrm{mg} / \mathrm{mq}$ i.v., day 1 every 2 weeks.

In the study population, according to RECIST criteria, $1 \mathrm{CR}$ and 23 PRs were reported, for an overall response rate (RR) of $28 \%$. Of the patients, $35(40 \%)$ achieved SD and $28(32 \%)$ experienced PD. At the time of the analysis, 81 (93\%) patients underwent disease progression and $63(72 \%)$ died. Median PFS and median OS were 4.1 and 9.7 months, respectively.

\section{Mutational status of KRAS codons 61 and 146}

The mutational analyses of codons 61 and 146 were successfully performed in 76 out of 87 cases. KRAS was mutated in codon 61 or 146 in $7(8 \%)$ and $1(1 \%)$ cases, respectively. None of the 8 patients bearing KRAS 61 or 146 mutated disease responded to the treatment, whereas $22(32 \%)$ of 68 patients with wild-type disease achieved response $(P=0.096$; Table 3B). KRAS 61 and 146 mutations were associated with significantly shorter PFS (median

Table 3 Study flow chart and correlations with response to treatment: (A) KRAS codons I2 and I3 analysis in the overall population; (B) KRAS 6 I and I46 mutations and (B) BRAF V600E mutation in study population (KRAS codons 12 and 13 subgroup)

A

\begin{tabular}{|l||c|c|c|}
\hline \multicolumn{3}{|c|}{ KRAS 12 and 13 mutations in the overall population } \\
\hline & $\begin{array}{c}\text { KRAS } 12 / 13 \text { mut } \\
N=51\end{array}$ & $\begin{array}{c}\text { KRAS } 12 / 13 \text { wt } \\
N=87\end{array}$ & Fisher's exact \\
& $48(94 \%)$ & $63(72 \%)$ & test: $P=0.004$ \\
\hline Non responders & $3(6 \%)$ & $24(28 \%)$ & \\
\hline Responders & $3(3)$ &
\end{tabular}

B

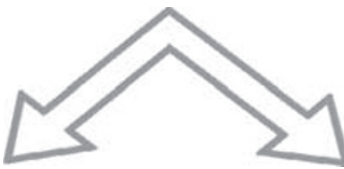

C

\begin{tabular}{|c|c|c|c|c|}
\hline & \multicolumn{4}{|c|}{ STUDY POPULATION (N=87) } \\
\hline & \multicolumn{2}{|c|}{ KRAS 61 and 146 mutations } & \multicolumn{2}{|c|}{ BRAF V600E mutation } \\
\hline & \multicolumn{2}{|c|}{$N=76$ (11 not evaluable) } & \multicolumn{2}{|c|}{$N=87$} \\
\hline & $\begin{array}{c}\text { KRAS } \begin{array}{c}61 / 146 \text { mut } \\
N=8\end{array} \\
\end{array}$ & $\begin{array}{c}\text { KRAS } 61 / 146 \mathrm{wt} \\
N=68\end{array}$ & $\begin{array}{c}B R A F \text { mut } \\
N=13\end{array}$ & $\begin{array}{c}\text { BRAF wt } \\
N=74\end{array}$ \\
\hline Non responders & $8(100 \%)$ & $46(68 \%)$ & $13(100 \%)$ & $50(68 \%)$ \\
\hline \multirow[t]{2}{*}{ Responders } & $0(0 \%)$ & $22(32 \%)$ & $0(0 \%)$ & $24(32 \%)$ \\
\hline & \multicolumn{2}{|c|}{ Fisher 's exact test: $P=0.096$} & \multicolumn{2}{|c|}{ Fisher 's exact test: $P=0.016$} \\
\hline
\end{tabular}



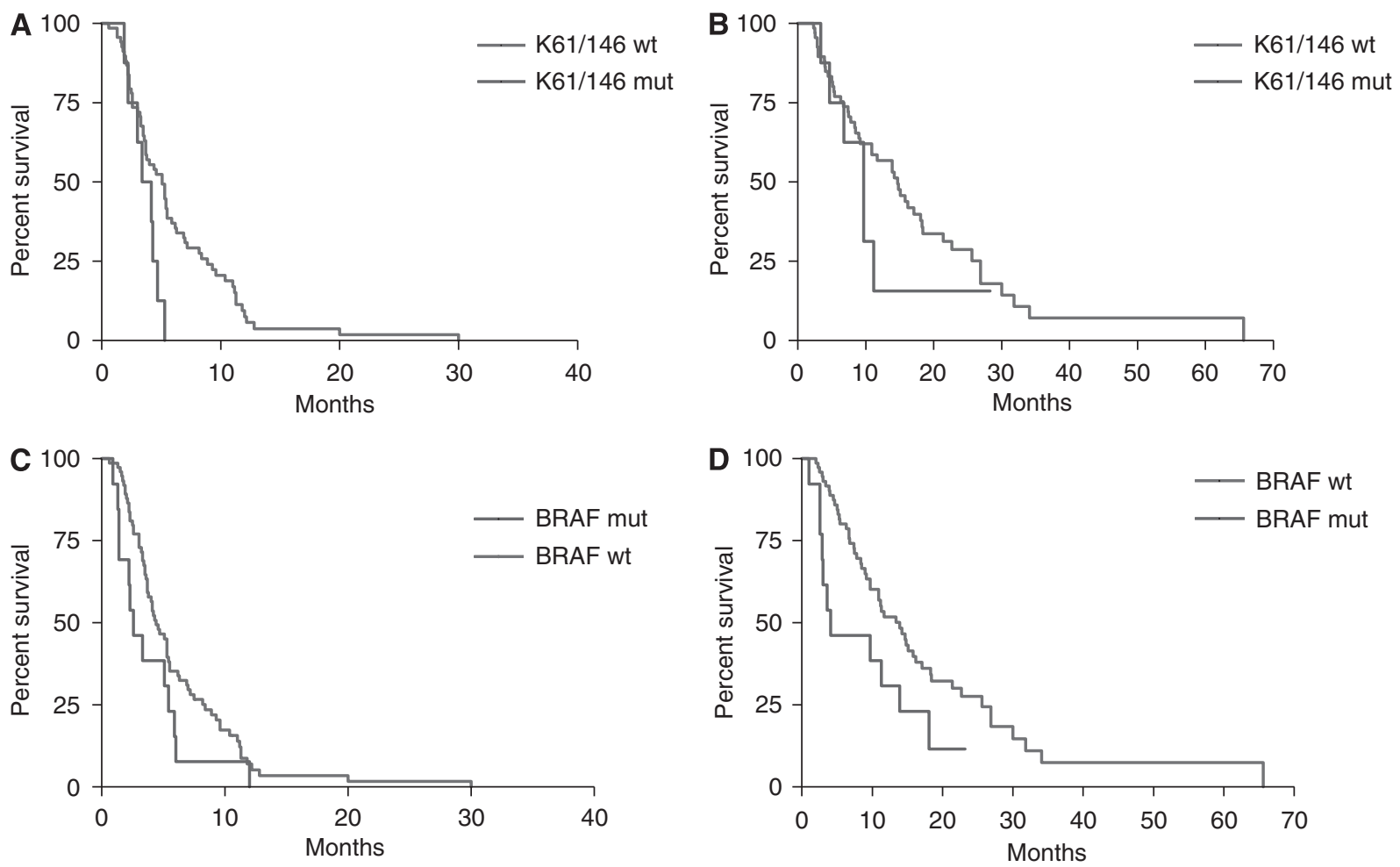

Figure I (A) Progression-free survival and (B) overall survival curves according to KRAS codons 6 I and I 46 mutational status in study population. (C) Progression-free survival and (D) overall survival curves according to BRAF codon 600 mutational status in study population.

PFS: 3.8 vs 5.1 months in KRAS 61 and 146 wild type; HR: 0.46 (0.11-0.88), $P=0.028$; Figure $1 \mathrm{~A})$, whereas no significant differences were detected in OS (median OS: 9.7 vs 14.7 months in KRAS 61 and 146 wild-type; HR: 0.69 (0.24-1.75), $P=0.390$; Figure $1 \mathrm{~B})$.

\section{Mutational status of BRAF codon 600}

Among the 87 patients of the study population, $B R A F$ was mutated in 13 cases (15\%). KRAS codons 61, 146 and BRAF V600E mutations were mutually exclusive. None of the patients bearing $B R A F$ mutation responded to the treatment, in comparison with $24(32 \%)$ of 74 patients with $B R A F$ wild-type disease $(P=0.016$; Table 3C). BRAF mutation was associated with a trend towards shorter PFS (median PFS: 2.6 vs 4.4 months in $B R A F$ wild-type; HR: 0.59 (0.24-1.07), $P=0.073$; Figure $1 C$ ) and with significantly shorter OS (median OS: 4.1 vs 13.9 months in BRAF wild-type; HR 0.51 (0.18-0.95), $P=0.037$; Figure 1D).

\section{Combined analysis of KRAS codons 61 and 146 and $B R A F$ codon 600 mutational status}

Among 74 patients with $B R A F$ wild-type disease, KRAS codons 61 and 146 mutational status was successfully assessed in 68 cases. Eight $(11 \%)$ tumours were KRAS 61 or 146 mutated. None of patients with KRAS 61 or 146 mutated tumours responded, in comparison with $22(37 \%)$ of 60 KRAS 61 and 146 wild-type patients $(P=0.047$; Table $4 \mathrm{~A})$. Also in $B R A F$ wild-type subpopulation, KRAS codons 61 and 146 mutations were associated with shorter PFS (median PFS: 3.8 vs 5.3 months in KRAS 61 and 146 wild-type; HR: $0.45(0.10-0.85), P=0.023$; Figure $2 \mathrm{~A}$ ), whereas no significant differences were reported in terms of OS (median OS: 9.7 vs 14.8 months in KRAS 61 and 146 wild-type; HR: 0.32 (0.21-1.66), $P=0.320$; Figure $2 B$ ).

In the subgroup of 68 patients with KRAS 61 and 146 wild-type tumours, $B R A F$ was mutated in 8 cases. None of $B R A F$-mutated
Table 4 (A) KRAS 6 I and 146 mutations in BRAF wild-type subgroup and (B) BRAF V600E mutation in KRAS 61 and 146 wild-type subgroup: correlation with response

A

\begin{tabular}{|l|c|c|}
\hline & $N=74$ (6 not evaluable) $\rightarrow 68$ evaluable \\
\hline & $\begin{array}{c}\text { KRAS } \begin{array}{c}61 / 146 \\
N=8\end{array} \\
\text { Non responders }\end{array}$ & $\begin{array}{c}\text { KRAS 61/146 wt } \\
N=60\end{array}$ \\
\hline Responders & $0(100 \%)$ & $38(63 \%)$ \\
\hline \multicolumn{3}{|c|}{ Fisher's exact test: $P=0.047$} \\
\hline
\end{tabular}

B

\begin{tabular}{|l|c|c|}
\hline & \multicolumn{2}{|c|}{$N=68$} \\
\hline & $\begin{array}{c}\text { BRAF mut } \\
N=8\end{array}$ & $\begin{array}{c}B R A F \text { wt } \\
N=60\end{array}$ \\
\hline Non responders & $8(100 \%)$ & $38(63 \%)$ \\
\hline Responders & $0(0 \%)$ & $22(37 \%)$ \\
\hline \multicolumn{2}{|c|}{ Fisher's exact test: $P=0.047$} \\
\hline
\end{tabular}

patients obtained a response, whereas $22(37 \%)$ out of 60 patients with $B R A F$ wild-type disease responded $(P=0.047$; Table $4 \mathrm{~B})$. $B R A F$ mutation was associated with a trend towards shorter PFS (median PFS: 3.9 vs 5.3 months in BRAF wild-type; HR: 0.69 (0.26$1.52), P=0.306$; Figure $3 \mathrm{~A}$ ) and OS (median OS: 9.0 vs 14.8 months in $B R A F$ wild-type; HR: $0.63(0.20-1.60), P=0.279$; Figure $3 B)$. 

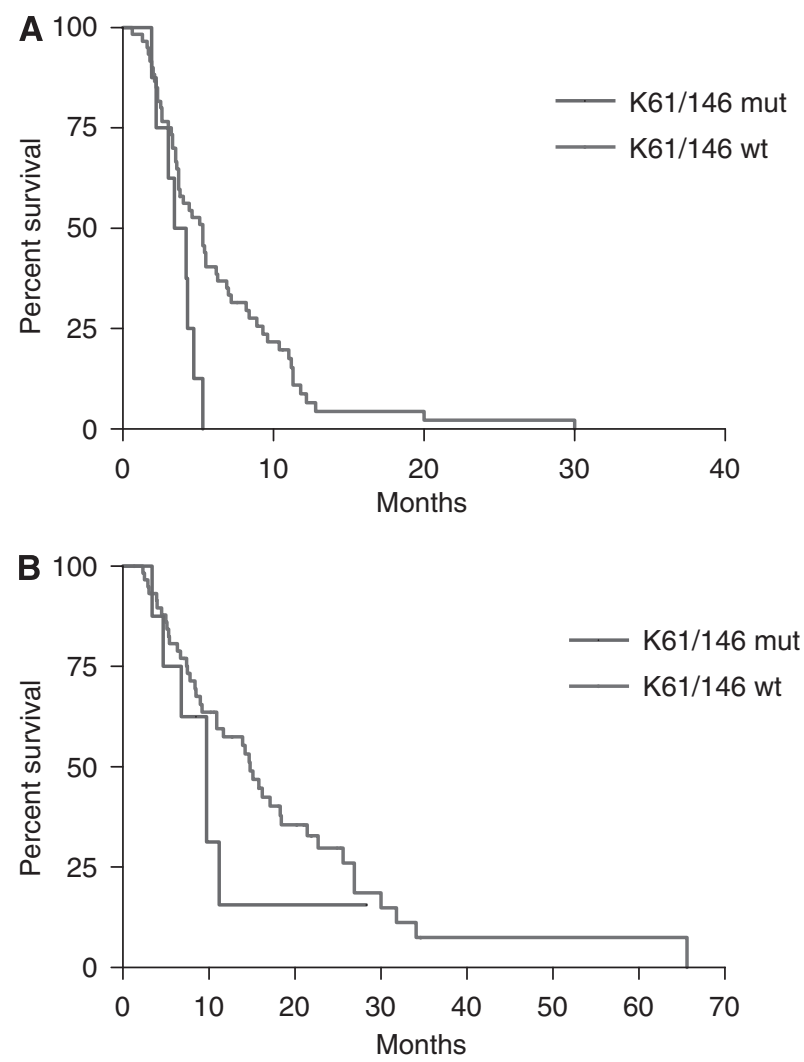

Figure 2 (A) Progression-free survival and (B) overall survival curves according to KRAS codons $6 I$ and I 46 mutational status in BRAF wild-type subgroup.
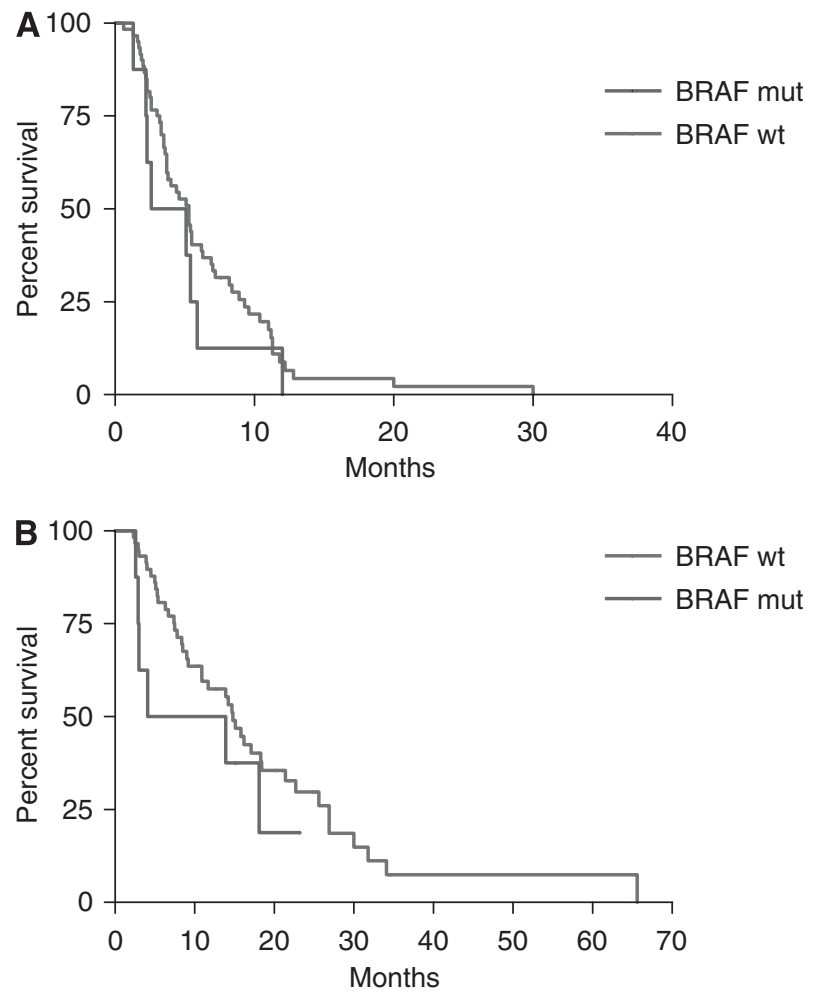

Figure 3 (A) Progression-free survival and (B) overall survival curves according to BRAF codon 600 mutational status in KRAS codon 61 and I46 wild-type subgroup.
Table 5 Combined analysis of KRAS 6I//46 and BRAF V600E mutation in study population: correlation with response

\begin{tabular}{|l|c|c|}
\hline & \multicolumn{2}{|c|}{$\begin{array}{c}\text { K=87 (6 not evaluable) } \rightarrow \text { 81 evaluable } \\
\text { BRAF mut } \\
N=21\end{array}$} \\
\hline & $\begin{array}{c}21(100 \%) \\
\text { KRAS } 61 / 146 \text { and BRAF } \\
\text { wt } \\
N=60\end{array}$ \\
\hline Non responders & $0(0 \%)$ & $38(63 \%)$ \\
\hline Responders & $22(37 \%)$ \\
\hline \multicolumn{3}{|c|}{ Fisher's exact test: $P=0.0005$} \\
\hline
\end{tabular}
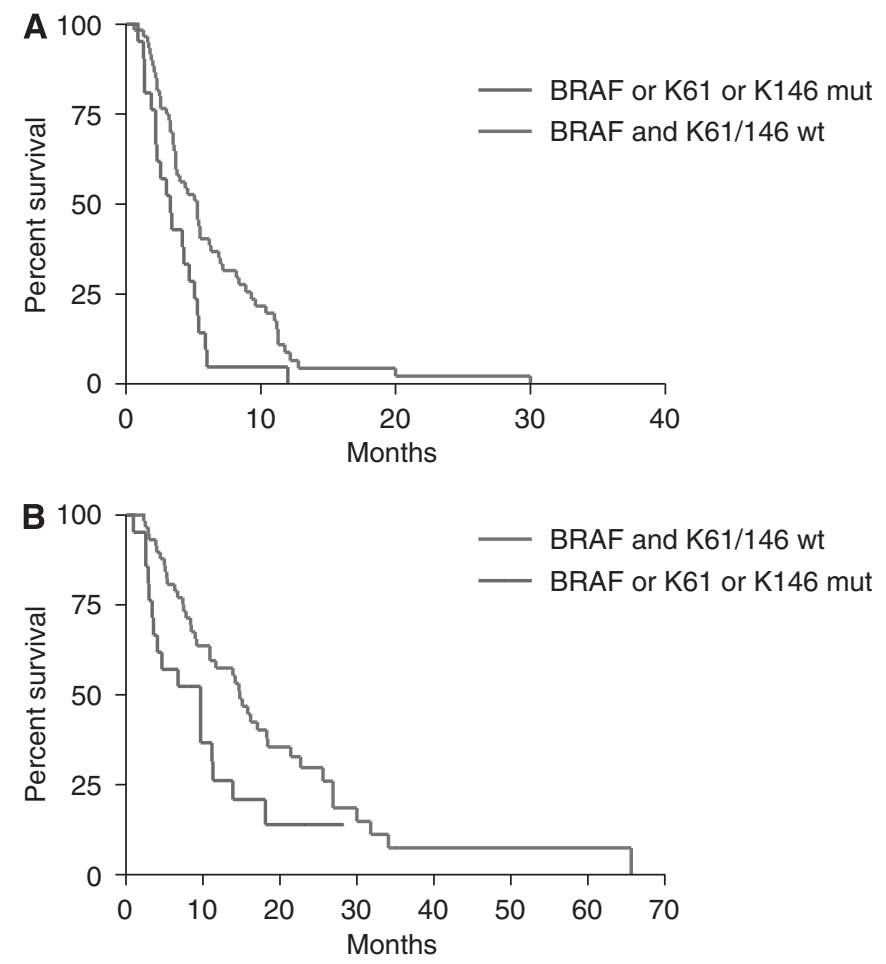

Figure 4 (A) Progression-free survival and (B) overall survival curves of patients with KRAS codon 6I or I46 or BRAF-mutated disease compared to those of patients with wild-type disease.

Among 87 patients of the study population, none of 21 patients with tumours presenting whatever mutation responded to the treatment, in comparison with $22(37 \%)$ of 60 patients with KRAS 61 and 146 and BRAF wild-type disease $(P=0.0005$; Table 5). Wild-type patients reported significantly longer PFS (median PFS: 5.3 vs 3.3 months; HR: $0.51(0.22-0.77), P=0.006$; Figure $4 \mathrm{~A})$ and OS (median OS: 14.8 vs 9.7 months; HR: 0.54 (0.24-0.92), $P=0.027$; Figure 4B).

\section{DISCUSSION}

The molecular test for KRAS mutations has been introduced in the routine clinical practice of the oncologists facing mCRC (Allegra et al, 2009). Since the first report of KRAS predictive value for resistance to cetuximab (Lièvre et al, 2006), investigators looked at most of the frequent mutations (ie, those affecting codons 12 and 13). Therefore, also the most reliable demonstrations of 
KRAS mutations as determinants of resistance to anti-EGFR moAbs, that is, those deriving from post hoc analyses of randomised studies (Karapetis et al, 2008; Amado et al, 2008; Van Cutsem et al, 2009), investigated only codons 12 and 13 genetic variants. Even if quite specific for non-responsiveness, KRAS codon 12 and 13 analysis suffers from low sensitivity. In fact around $35 \%$ of wild-type patients experience rapid disease progression.

This background led to the search for alternative predictive factors, such as EGFR ligands expression (Khambata-Ford et al, 2007) or polymorphisms (Garm Spindler et al, 2009), alterations in other EGFR signalling pathways (ie, PTEN/PI3K/AKT; Loupakis et al, 2009) or in downstream effectors of KRAS (ie, BRAF). In particular, Di Nicolantonio et al (2008) recently found that none of $11 B R A F$-mutated patients, among 79 KRAS codon 12 and 13 wild type, responded to anti-EGFR moAbs. BRAF mutation also predicted for an unfavourable outcome in terms of both PFS and OS. From a methodological standpoint mutational analyses are quite more appealing with respect to other techniques such as immunohistochemistry or gene expression profiling. In fact, the determination of mutational status is easily reproducible, qualitative, less expensive and does not require fresh tumour tissue sampling. Taking into account these considerations and the growing knowledge on minor oncogenic KRAS mutations in codons 61 and 146 (mutually exclusive with those in codons 12 and 13 ), we conducted this retrospective study to verify whether the combined analyses of such rare KRAS mutations and BRAF codon 600 variants are related to resistance to cetuximab plus irinotecan. In the present analysis, 13,7 and 1 patient among 87 patients with KRAS codon 12 and 13 wild-type disease had tumour bearing $B R A F$ V600E, KRAS codon 61 and KRAS codon 146 mutation, respectively. None of the KRAS codon 12 or 13 wild-type patients bearing an alteration on KRAS codon 61,146 or BRAF codon 600 responded to treatment. Moreover patients with mutated tumours had a significantly worse outcome both in terms of PFS and OS. Such data indicate that, even if much more rare than codon 12 or 13 mutations, codon 61 and 146 as well as BRAF mutations also seem to predict resistance to cetuximab. As these rare $K R A S$ mutations and $B R A F$ mutations are mutually exclusive with the others, it seems reasonable to test for their presence only in patients with KRAS codon 12 and 13 wild-type tumours.

\section{REFERENCES}

Adam R, Wicherts DA, de Haas RJ, Ciacio O, Levi F, Paule B, Ducreux M, Azoulay D, Bismuth H, Castaing D (2009) Patients with initially unresectable colorectal liver metastases: is there a possibility of cure? J Clin Oncol 27(11): 1829-1835

Allegra CJ, Jessup JM, Somerfield MR, Hamilton SR, Hammond EH, Hayes DF, McAllister PK, Morton RF, Schilsky RL (2009) American Society of Clinical Oncology provisional clinical opinion: testing for KRAS gene mutations in patients with metastatic colorectal carcinoma to predict response to anti-epidermal growth factor receptor monoclonal antibody therapy. J Clin Oncol 27(12): 2091-2096

Amado RG, Wolf M, Peeters M, Van Cutsem E, Siena S, Freeman DJ, Juan T, Sikorski R, Suggs S, Radinsky R, Patterson SD, Chang DD (2008) Wild-type KRAS is required for panitumumab efficacy in patients with metastatic colorectal cancer. J Clin Oncol 26(10): 1626-1634

Bos JL (1989) Ras oncogenes in human cancer: a review. Cancer Res 49(17): $4682-4689$

Buhrman G, Wink G, Mattos C (2007) Transformation efficiency of RasQ61 mutants linked to structural features of the switch regions in the presence of Raf. Structure 15(12): 1618-1629

Conlin A, Smith G, Carey FA, Wolf CR, Steele RJ (2005) The prognostic significance of K-ras, p53, and APC mutations in colorectal carcinoma. Gut 54(9): $1283-1286$

Cunningham D, Humblet Y, Siena S, Khayat D, Bleiberg H, Santoro A, Bets D, Mueser M, Harstrick A, Verslype C, Chau I, Van Cutsem E (2004) Cetuximab monotherapy and cetuximab plus irinotecan in irinotecanrefractory metastatic colorectal cancer. $N$ Engl J Med 351(4): 337-345
Considering our data, it seems that among those subjects that are expected not to have codon 12 or 13 mutations (around $60 \%$ of mCRC patients), testing for BRAF and rare KRAS mutations would exclude around $25 \%$ of patients, with obvious saving of economic resources and sparing unnecessary toxicities.

The quest for the most sensible and specific tools for selecting patients who are more likely to benefit from anti-EGFR inhibitors is an issue acquiring a great relevance for two main reasons. On one hand, in addition to the present indication for the use of antiEGFR moAbs, the results from a recent phase III randomised trial (Van Cutsem et al, 2009) led to the approval of cetuximab for KRAS codon 12 and 13 wild-type patients also in the first-line setting. On the other hand, it has been proven that in such setting the choice of using an anti-EGFR moAb precludes the possibility of coadministering the antiangiogenic antibody bevacizumab, even in KRAS codon 12 and 13 wild-type patients (Tol et al, 2009; Hecht et al, 2009). Moreover, it should be noted that the choice of the best upfront treatment for each patient is not only to offer the best palliation, but it may even influence the possibility for cure (Adam et al, 2009). In this regard it should be considered that there are different ongoing randomised studies evaluating the impact of moAbs in the adjuvant setting, where the clinical impact of reliable predictors of outcome will be even greater.

In conclusion, our results suggest that KRAS testing power for predicting resistance to anti-EGFR might be improved by including codon 61 and 146 mutational analysis. This finding may have rapid and important implications for routine clinical practice. Moreover, this study confirms the recent finding that indicates $B R A F$ V600E mutation as a promising additional marker for resistance. Such preliminary and retrospective results should be verified on samples from patients enrolled in randomised studies of anti-EGFR moAbs $v s$ best supportive care.

\section{ACKNOWLEDGEMENTS}

This study was supported by grants from Consorzio Interuniversitario per le Biotecnologie (CIB), Fanoateneo and Associazione Ricerca e Cure in Oncologia (ARCO).
Di Nicolantonio F, Martini M, Molinari F, Sartore-Bianchi A, Arena S, Saletti P, De Dosso S, Mazzucchelli L, Frattini M, Siena S, Bardelli A (2008) Wild-type BRAF is required for response to panitumumab or cetuximab in metastatic colorectal cancer. J Clin Oncol 26(35): $5705-5712$

Edkins S, O’Meara S, Parker A, Stevens C, Reis M, Jones S, Greenman C, Davies H, Dalgliesh G, Forbes S, Hunter C, Smith R, Stephens P, Goldstraw P, Nicholson A, Chan TL, Velculescu VE, Yuen ST, Leung SY, Stratton MR, Futreal PA (2006) Recurrent KRAS codon 146 mutations in human colorectal cancer. Cancer Biol Ther 5(8): 928 -932

EMEA (2008) Committee for Medicinal Products for Human Use postauthorisation summary of positive opinion for Erbitux. http://wwwemeaeuropaeu/pdfs/human/opinion/Erbitux _28040208enpdf

Feig LA, Cooper GM (1988) Relationship among guanine nucleotide exchange, GTP hydrolysis, and transforming potential of mutated ras proteins. Mol Cell Biol 8(6): 2472-2478

Garm Spindler KL, Pallisgaard N, Rasmussen AA, Lindebjerg J, Andersen RF, Cruger D, Jakobsen A (2009) The importance of KRAS mutations and EGF61A $>$ G polymorphism to the effect of cetuximab and irinotecan in metastatic colorectal cancer. Ann Oncol 20(5): 879-884

Hecht JR, Mitchell E, Chidiac T, Scroggin C, Hagenstad C, Spigel D, Marshall J, Cohn A, McCollum D, Stella P, Deeter R, Shahin S, Amado RG (2009) A randomized phase IIIB trial of chemotherapy, bevacizumab, and panitumumab compared with chemotherapy and bevacizumab alone for metastatic colorectal cancer. J Clin Oncol 27(5): $672-680$ 
Jonker DJ, O'Callaghan CJ, Karapetis CS, Zalcberg JR, Tu D, Au HJ, Berry SR, Krahn M, Price T, Simes RJ, Tebbutt NC, van Hazel G, Wierzbicki R, Langer C, Moore MJ (2007) Cetuximab for the treatment of colorectal cancer. N Engl J Med 357(20): 2040-2048

Karapetis CS, Khambata-Ford S, Jonker DJ, O'Callaghan CJ, Tu D, Tebbutt NC, Simes RJ, Chalchal H, Shapiro JD, Robitaille S, Price TJ, Shepherd L, Au HJ, Langer C, Moore MJ, Zalcberg JR (2008) K-ras mutations and benefit from cetuximab in advanced colorectal cancer. $N$ Engl J Med 359(17): $1757-1765$

Khambata-Ford S, Garrett CR, Meropol NJ, Basik M, Harbison CT, Wu S, Wong TW, Huang X, Takimoto CH, Godwin AK, Tan BR, Krishnamurthi SS, Burris III HA, Poplin EA, Hidalgo M, Baselga J, Clark EA, Mauro DJ (2007) Expression of epiregulin and amphiregulin and K-ras mutation status predict disease control in metastatic colorectal cancer patients treated with cetuximab. J Clin Oncol 25(22): 3230-3237

Lièvre A, Bachet JB, Le Corre D, Boige V, Landi B, Emile JF, Côté JF, Tomasic G, Penna C, Ducreux M, Rougier P, Penault-Llorca F, LaurentPuig P (2006) KRAS mutation status is predictive of response to cetuximab therapy in colorectal cancer. Cancer Res 66(8): 3992-3995

Linardou H, Dahabreh I, Kanaloupiti D, Siannis F, Bafaloukos D, Kosmidis P, Papadimitriou CA, Murray S (2008) Assessment of somatic k-RAS mutations as a mechanism associated with resistance to EGFR-targeted agents: a systematic review and meta-analysis of studies in advanced non-small-cell lung cancer and metastatic colorectal cancer. Lancet Oncol 9(10): 962-972

Loupakis F, Pollina L, Stasi I, Ruzzo A, Scartozzi M, Santini D, Masi G, Graziano F, Cremolini C, Rulli E, Canestrari E, Funel N, Schiavon G, Petrini I, Magnani M, Tonini G, Campani D, Foriani I, Cascinu S, Falcone A (2009) PTEN Expression and KRAS Mutations on Primaries and Metastases in the Prediction of Benefit From Cetuximab Plus Irinotecan for Patients With Metastatic Colorectal Cancer. J Clin Oncol 27(16): $2622-2629$
Therasse P, Arbuck SG, Eisenhauer EA, Wanders J, Kaplan RS, Rubinstein L, Verweij J, Van Glabbeke M, van Oosterom AT, Christian MC, Gwyther SG (2000) New guidelines to evaluate the response to treatment in solid tumors. European Organization for Research and Treatment of Cancer, National Cancer Institute of the United States, National Cancer Institute of Canada. J Natl Cancer Inst 92(3): 205-216

Tol J, Koopman M, Cats A, Rodenburg CJ, Creemers GJ, Schrama JG, Erdkamp FL, Vos AH, van Groeningen CJ, Sinnige HA, Richel DJ, Voest EE, Dijkstra JR, Vink-Börger ME, Antonini NF, Mol L, van Krieken JH, Dalesio O, Punt CJ (2009) Chemotherapy, bevacizumab, and cetuximab in metastatic colorectal cancer. $N$ Engl J Med 360(6): $563-572$

Van Cutsem E, Kohne CH, Hitre E, Zaluski J, Chang Chien CR, Makhson A, D'haens G, Pintér T, Lim R, Bodoky G, Roh JK, Folprecht G, Ruff P, Stroh C, Tejpar S, Schlichting M, Nippgen J, Rougier P (2009) Cetuximab and chemotherapy as initial treatment for metastatic colorectal cancer. $N$ Engl J Med 360(14): $1408-1417$

Van Cutsem E, Peeters M, Siena S, Humblet Y, Hendlisz A, Neyns B, Canon JL, Van Laethem JL, Maurel J, Richardson G, Wolf M, Amado RG (2007) Open-label phase III trial of panitumumab plus best supportive care compared with best supportive care alone in patients with chemotherapy-refractory metastatic colorectal cancer. J Clin Oncol 25(13): $1658-1664$

Wan PT, Garnett MJ, Roe SM, Lee S, Niculescu-Duvaz D, Good VM, Jones CM, Marshall CJ, Springer CJ, Barford D, Marais R, Cancer Genome Project (2004) Mechanism of activation of the RAF-ERK signaling pathway by oncogenic mutations of B-RAF. Cell 116(6): 855-867

Wickenden JA, Jin H, Johnson M, Gillings AS, Newson C, Austin M, Chell SD, Balmanno K, Pritchard CA, Cook SJ (2008) Colorectal cancer cells with the BRAF(V600E) mutation are addicted to the ERK1/2 pathway for growth factor-independent survival and repression of BIM. Oncogene 27(57): $7150-7156$ 